ConNotas. Revista de crítica y teoría literarias / Vol. V, Núm. 9 / 2007

\title{
Constructo figural del dictador y efectos de lectura en El Seductor de la Patria
}

\author{
Ana Bertha de la Vara Estrada* \\ Fortino CORRAL RodRÍGUEZ*
}

Resumen:

Antonio López de Santa Anna, el protagonista de El seductor de la patria, es precedido abrumadoramente por su homónimo histórico. La lectura de la novela implica, pues, una obligada confrontación entre el estereotipo cultural y el personaje novelesco construido por Enrique Serna. Por otra parte, la novela guarda fuertes vínculos temáticos y formales con la llamada novela de la dictadura hispanoamericana, lo cual confiere al personaje central ciertas determinaciones. En este trabajo se analiza la configuración del protagonista, teniendo en cuenta los recursos narrativos empleados en la representación de la conciencia figural, los elementos textuales y contextuales que participan en la articulación discursiva de la novela y los efectos de lectura derivados de la composición en su conjunto.

Palabras clave:

Literatura mexicana, Antonio López de Santa Anna, Enrique Serna, dictadura, personaje referencial.

La "novela de la dictadura" adquiere especial fisonomía como género o subsistema literario en la década de los setenta, pero cuenta con antecedentes y subsecuentes; los primeros se remontan al siglo XIX, y los segundos se adentran en el siglo XXI. La configuración

\footnotetext{
* Ambos, Universidad de Sonora.
} 
del protagonista de estas novelas merece un examen especial por varias razones. En primer lugar, se trata de personajes que trascienden el marco del relato literario pues remiten a constructos culturales e históricos cargados de significado social. Por otra parte, las innovaciones artísticas promovidas por el llamado boom de los años sesenta conducen a una mayor profundización en la interioridad del personaje dictador (Benedetti); ¿se traduce esta cercanía en una humanización del estereotipo? De ser así, el espíritu combativo que, según Carlos Pacheco y otros críticos, anima a este ciclo literario se vería sustancialmente afectado.

El protagonista de estas novelas constituye una categoría particular de personaje: aquel que reinventa un modelo que le precede, como es el caso del "pícaro", el "don Juan”, o ciertas figuras históricas como Hitler, y míticas como Sísifo o Apolo; Hamon denomina referenciales a estos personajes, los cuales remiten "a un sentido pleno y fijo, inmovilizado por la cultura, a roles, programas y usos estereotipados, y su legibilidad depende del grado de participación y conocimiento del lector" (Citado por Pimentel 64).

En las "novelas de dictadura", los personajes adoptan dos formas básicas en relación con sus referentes históricos: puede ocurrir que se configuren a modo de síntesis de varios dictadores latinoamericanos, como se aprecia en El recurso del método (1974) de Alejo Carpentier y El otoño del Patriarca (1975) de Gabriel García Márquez, o bien, que representen a un dictador específico como ocurre en $Y_{o}$ el supremo (1974) de Augusto Roa Bastos y en la novela que nos ocupa, El seductor de la patria (1999) del mexicano Enrique Serna.

El protagonista de El seductor de la patria, Antonio López de Santa Anna, es precedido abrumadoramente por su homónimo histórico: en efecto, López de Santa Anna es una de las figuras históricas más abominables que pueblan el imaginario popular mexicano, apenas superada por la de don Porfirio Díaz. A Santa Anna se le responsabiliza de un hecho histórico imperdonable: la mutilación territorial que sufre el país a manos de Estados Unidos a mediados del siglo XIX; a ello se agregan conductas despóticas como ocupar y abandonar la presidencia en once ocasiones, en las que se comporta como un mandatario caprichoso, ególatra y corrupto, todo lo cual 
le confiere un perfil de dictador. Ya en 1938 Rafael F. Muñoz le da ese calificativo en el título de su biografía (¿novela?): Santa Anna, el dictador resplandeciente.

La narratología ofrece muy pocos instrumentos teórico-metodológicos para el análisis de personaje, pese a que, como bien lo señala Bustillo, "los personajes son los principales portadores de significación de los universos ficticios" (19). En nuestro análisis tomaremos como punto de partida la distinción que hace Mijaíl Bajtín entre dos modelos básicos: uno, de tipo tradicional, en el que el héroe representa un tipo social, con rasgos definidos y fijados desde el exterior, y dos: el héroe como "punto de vista particular sobre el mundo y sobre sí mismo" (Bajtín 71, subrayado por el autor); en esta segunda modalidad no se busca caracterizar o representar una imagen firme de un ente social "sino que viene a ser el último recuento de su conciencia y autoconciencia y al fin y al cabo, su última palabra acerca de su persona y de su mundo" (72).

¿En qué categoría se ubica el héroe de El seductor de la patria? Resulta un tanto inadecuado considerar de manera abrupta la distinción anterior. Habría que identificar estas dos modalidades como direcciones básicas en la configuración de la conciencia figural y no como tipos de personaje novelesco. Lo que está en juego es el potencial del personaje para constituirse como una perspectiva particular sobre el mundo o si, por el contrario, su autonomía se desdibuja a un grado tal que se le percibe como instrumento vocal del autor; es de suponerse que entre menos densidad ética posea el personaje, mayor es la determinación que ejerce el autor sobre él.

Significativamente, la novela El seductor comienza abruptamente, sin mediación narrativa alguna, con una carta que Santa Anna dirige a su hijo Manuel. En ella le habla de la decadencia cotidiana en que transcurre su vejez, de sus impedimentos físicos que lo hacen depender de los cuidados de su esposa y confiesa su sentir respecto a sus aspiraciones íntimas en el terreno político:

A un paso de la tumba, después de 18 años en el exilio y a pesar de las humillaciones que he padecido, todavía espero recuperar la estimación del pueblo [...] Daría la poca vida que 
me queda por limpiar mi nombre y recibir el postrer homenaje de mis compatriotas. (13-14)

Queda explícito pues, el deseo que motiva la acción del personaje: reivindicar su imagen ante la sociedad. En la segunda carta queda claro el medio a través del cual se propone dar cumplimiento a tal objetivo: "Pero lo que más me interesa es el tribunal de la historia. Para revocar su fallo adverso necesito un biógrafo de mi entera confianza, que muestre mi lado humano a las generaciones futuras. ¿Sería mucho pedirte que tú lo fueras?” (18). Más adelante, en la tercera carta, Santa Anna hace recomendaciones sobre la manera en que desea verse reflejado y recomienda estrategias discursivas para que la biografía logre su objetivo:

[...] en tu biografía quiero aparecer retratado de cuerpo entero, como el hombre temperamental y voluble que fui. No disimules mis defectos. La obra será más convincente si en vez de ocultar mis debilidades las pones en primer plano, minimizadas -eso sí- por mis actos de valentía y heroísmo... censúrame un poco para que la gente dé mayor crédito al relato. Con ello te echarás a la bolsa al lector y no dudará de tu palabra. (19-20)

A semejanza de lo que ocurre en Yo el supremo, el protagonista de El seductor se propone dictar su biografía, pero con la diferencia de que aquél se halla en pleno ejercicio del poder cuando emprende su acto escritural; Santa Anna, en cambio, se encuentra excluido totalmente de la esfera política, carece de recursos económicos para sobrellevar una vida digna, y su autoridad se halla totalmente maltrecha al grado que cojea aún en el ámbito doméstico. La primera carta que envía a su hijo va acompañada de una posdata escrita a sus espaldas por Dolores Tosta, su mujer, en la que ella dice cosas como ésta: "Créeme, no es nada grato vivir atada a un anciano con delirios de grandeza que a la menor impresión se orina en los pantalones" (16). La mujer posee el control del medio de comunicación empleado por Santa Anna: indica al destinatario que en adelante 
las cartas llevarán escrito el remitente de ella para evitar la censura oficial, y contraviene olímpicamente la voluntad de quien se hiciera llamar su Alteza Serenísima: "Y otro favor: no le mandes los puros. El doctor le prohibió fumar porque está enfermo de la garganta" (17).

La escritura autobiográfica supone un autoexamen por parte del autor-personaje; sin embargo, este género suele responder a propósitos exculpatorios, antes que a necesidades introspectivas. En el caso de Santa Anna, vemos a un hombre preocupado por su imagen pública, en cuyo discurso la aceptación de yerros y debilidades obedece más a una concesión retórica que a una autocrítica:

Se me acusa de traición a la patria, de enriquecimiento ilícito con la venta de La Mesilla, de la pérdida de Texas, de la bancarrota pública. Tal parece que soy el culpable de todos los desastres ocurridos en los últimos 50 años, incluyendo terremotos y epidemias de cólera. Como todo ser humano he cometido yerros, y algunos de ellos tuvieron consecuencias funestas... Pero de ahí a la monstruosidad que me achacan hay un abismo... Gran parte de mis culpas le corresponde a la sociedad que ahora me crucifica. ¿O acaso goberné un país de niños? Nadie, ni el más feroz de mis enemigos puede negar que la mayoría de las veces acepté la presidencia obligado por la presión popular, después de infinitos ruegos. (17-18)

Por otra parte, la organización de la novela proyecta en el personaje algunas determinaciones que es necesario examinar. En lo básico, El seductor adopta la forma de novela epistolar, aunque integra, además de las cartas, textos de diverso tipo: diarios, proclamas, entrevistas, informes militares, actas notariales, contratos de compraventa, etc.

El carácter fragmentado de la novela, por otra parte, no deriva en caos, sino que se mantiene como un todo orgánico. Su consistencia radica en gran medida en su ensamblaje discursivo que se basa en tres núcleos escriturales, los cuales se corresponden con sendos personajes: Santa Anna, quien dicta sus cartas autobiográ- 
ficas; Manuel María Giménez, quien funge como su secretario; y Manuel, hijo de Santa Anna, destinatario de sus cartas y escribiente a su vez de otras.

La mediación del secretario constituye un elemento desestabilizador con respecto a la palabra del protagonista, lo cual comienza a darse desde las primeras páginas; la tercer carta de Santa Anna inicia con esta aclaración: "Te escribo con una caligrafía más clara, pues ahora tengo un secretario que se ha ofrecido a ayudarme sin cobrar un centavo [...] Le tengo absoluta confianza y puedo dictarle sin temor a que cometa indiscreciones" (33).

La confiabilidad del amanuense, sin embargo, deja mucho que desear para el biógrafo en ciernes:

¿Quiere usted falsear su biografía para complacer a un país de hipócritas y ladrones? [...] ¿Con qué derecho se atreve a escamotearme las transcripciones de sus monólogos? [...] advierto en usted una tendencia a colocarse en el primer plano de la historia [...] Modérese un poco, Giménez, y ponga los pies en la tierra. Si en verdad quiere honrar la memoria del viejo, registre sus palabras con escrupulosa fidelidad no importa si pierde la cabeza o se autodenigra: ya decidiré yo lo que se puede publicar o no. (292)

Aunque se trata de una novela fragmentada en la que cartas y documentos se siguen unos a otros sin la mediación de una $\mathrm{VOZ}$ narrativa que explicite su sentido, el lector pronto advierte que no es el mero azar el que rige el orden de los materiales, sino que a éste subyace una intencionalidad. La palabra de Santa Anna sufre constantemente la embestida de documentos ajenos que ponen en tela de duda la autenticidad de sus aseveraciones. Considérese por ejemplo este pasaje en que manifiesta su aprecio pretérito por Iturbide: "Para ser franco, yo apoyaba con entusiasmo la manera como Iturbide estaba llevando las cosas, y creía ingenuamente en la sinceridad de sus atenciones. Me fui a Puebla creyendo que me tenía en alta estima..." (92). El texto que sigue a éste es justo una carta de Iturbide dirigida a José Joaquín de Herrera en la que comenta: 
He conocido a nuestro coronel Santa Anna y concuerdo plenamente con la descripción que usted me había hecho de su persona. En mi vida he soportado a un adulador más irritante, y eso que las últimas semanas, por las inminencias del triunfo, vienen a verme lambiscones de la peor calaña. (92)

Tenemos, pues, una cuarta instancia organizativa, sumamente discreta, que es la encargada de colocar en forma significativa los materiales que integran la novela. Esta instancia toma el nombre de "compilador" y se manifiesta sólo una vez en la novela y lo hace en nota de pie de página (125).

Llama la atención que el personaje (Santa Anna) resulta ser un reverendo pillo al que se le pueden colgar muchos otros epítetos denigrantes y ninguno se le cae: cobarde, oportunista, traidor, lambiscón, ignorante, irresponsable, frívolo, ambicioso, corrupto, megalómano, etc. Sin embargo, curiosamente no hay en la novela soporte suficiente para colocarle el calificativo de tirano o de dictador... No se le ve ejerciendo un poder omnímodo y despótico sobre sus subordinados; no se le ve ocupado en instrumentar sistemas de vigilancia y represión policial contra el pueblo que gobierna. Por el contrario, el poder fáctico parece incomodarle una vez que lo obtiene: "El poder es una agilidad cargada con cadenas, uno termina por volverse esclavo de su puesto. Pero yo no me dejaré encerrar en Palacio nacional: he decidido fijar mi residencia en Tacubaya" (294). La dictadura es, sin embargo, una aspiración admitida por Santa Anna, pero una aspiración que queda frustrada, según la valoración que él mismo hace de su paso por el poder:

Lo que pasa es que en la presidencia de la República sólo ejercía el poder de palabra, pero no de facto. Por culpa de los partidos y las banderías nunca pude hacer las cosas a mi modo, salvo en el breve periodo de mi dictadura, y aún entonces tropecé con la oposición de mis propios ministros, divididos en bandos antagónicos... siempre estuve atado de manos... ¡Cuántas veces mis propios aliados me negaron dinero para embellecer la capital, para fomentar la industria, para vestir al ejército con uniformes dignos! (72) 
A modo de conclusión, la organización textual prefigura una serie de efectos de lectura, entre los cuales pueden considerarse, siempre de manera hipotética, los siguientes:

1. Relación lector-personaje. El lector medio se enfrenta inicialmente al texto predispuesto a intensificar el repudio que corresponde al personaje histórico que se recrea. Sin embargo, en las primeras páginas tal expectativa experimenta un reacomodo al encontrarse con un personaje estrafalario, pero desvalido, impedido materialmente para causar daño alguno.

2. Interacción del lector con el texto. El lector se percata pronto de que la novela no proporciona un punto de vista explícito sobre el mundo narrado, sino que le presenta una serie de documentos para que haga sus propias conjeturas sobre el personaje.

3. Posicionamiento del lector respecto a la información. El lector se complace en jugar una posición privilegiada de observador indiscreto; accede a información valiosa que el protagonista no controla o, incluso, no conoce. La novela se le presenta como un material abundante y heterogéneo que aún no es el libro en que habrá de convertirse ya que el biógrafo novelado no ha realizado aún su trabajo de selección y manipulación.

4. El lector como biógrafo. El seductor de la patria se presenta, en cierto modo, como un libro en proyecto y ese libro en ciernes ha de ser una biografía legitimadora del dictador. El hecho de interceptar el material que habrá de utilizarse en su elaboración hace del lector un biógrafo alterno.

5. Participación constructiva del lector. Para reinventar al personaje, el lector cuenta sólo con reflejos parciales: los documentos varios que por lo general delatan acciones reprobables del protagonista y las cartas autobiográficas dictadas por Santa Anna al secretario, textos adulterados en alguna forma por la mediación de que son objeto. Los primeros producen un efecto de objetividad histórica sobre las fechorías del personaje, mientras que la palabra de él resulta poco confiable. 
6. Se da un efecto de desenmascaramiento en el que presuntamente asoma el verdadero rostro, el rostro humano, del otrora "Benemérito de la patria". Pero este efecto de humanización resulta no tanto de que el personaje adquiera una profundidad ética o emocional, sino porque se le despoja de toda heroicidad.

\section{Bibliografía}

Bajtín M. Mijaíl. Problemas de la poética de Dostoievski. Tr. Tatiana Bubnova. Col. Breviarios 417. México: Fondo de Cultura Económica, 1986.

Benedetti, Mario. El recurso del supremo patriarca. México: Editorial Nueva Imagen, 1979.

Bustillo, Carmen. El ente de papel. Un estudio del personaje en la narrativa latinoamericana. Caracas: Vandel Hermanos, 1995.

Pacheco, Carlos. Narrativa de la dictadura y crítica literaria. Venezuela: CELARG, 1987.

Pimentel, Luz Aurora. El relato en perspectiva. Estudio de teoría narrativa. México: Siglo XXI, 1998.

Serna, Enrique. El seductor de la patria. México: Joaquín Mortiz, 2005. 